\title{
Mechanoenergetics Characterizing Oxygen Wasting Effect of Caffeine in Canine Left Ventricle
}

\author{
Toshiyuki TAKASAGo*, ${ }^{*}$, Yoichi GOTO*, Katsuya HATA*, Akio SAEKI*, \\ Takehiko NISHIOKA*, Tad W. TAYLOR* ${ }^{*}$, Gentaro IRIBE ${ }^{\ddagger}$, \\ Satoshi MOHRI ${ }^{\ddagger}$, Juichiro SHIMIZU ${ }^{\ddagger}$, Junichi ARAKI ${ }^{\ddagger}$, \\ and Hiroyuki SUGA ${ }^{*, \neq}$ \\ *National Cardiovascular Center, Suita, 565-8565 Japan; 'Baba Hospital, \\ Takehara, 725-0012 Japan; and FDepartment of Physiology II, \\ Okayama University Medical School, Okayama, 700-8558 Japan
}

\begin{abstract}
Caffeine causes a considerable $\mathrm{O}_{2}$ waste for positive inotropism in myocardium by complex pharmacological mechanisms. However, no quantitative study has yet characterized the mechanoenergetics of caffeine, particularly its $\mathrm{O}_{2}$ cost of contractility in the $E_{\max }-\mathrm{PVA}-\mathrm{VO}_{2}$ framework. Here, $E_{\max }$ is an index of ventricular contractility, PVA is a measure of total mechanical energy generated by ventricular contraction, and $\mathrm{VO}_{2}$ is $\mathrm{O}_{2}$ consumption of ventricular contraction. The $E_{\max }-\mathrm{PVA}-\mathrm{VO}_{2}$ framework proved to be powerful in cardiac mechanoenergetics. We therefore studied the effects of intracoronary caffeine at concentrations lower than $1 \mathrm{mmol} / /$ on left ventricular (LV) $E_{\max }$ and $\mathrm{VO}_{2}$ for excitationcontraction (E-C) coupling in the excised crosscirculated canine heart. We enhanced LV $E_{\max }$ by
\end{abstract}

intracoronary infusion of caffeine after $\beta$-blockade with propranolol and compared this effect with that of calcium. We obtained the relation between LV $V_{\mathrm{O}_{2}}$ and PVA with $E_{\max }$ as a parameter. We then calculated the $\mathrm{VO}_{2}$ for the $\mathrm{E}-\mathrm{C}$ coupling by subtracting $\mathrm{VO}_{2}$ under $\mathrm{KCl}$ arrest from the PVA-independent (or zero-PVA) $\mathrm{VO}_{2}$ and the $\mathrm{O}_{2}$ cost of $E_{\max }$ as the slope of the E-C coupling $\mathrm{VO}_{2}-E_{\max }$ relation. We found that this cost was $40 \%$ greater on average for caffeine than for calcium. This result, for the first time, characterized integratively cardiac mechanoenergetics of the $\mathrm{O}_{2}$ wasting effect of the complex inotropic mechanisms of intracoronary caffeine at concentrations lower than $1 \mathrm{mmol} / /$ in a beating whole heart. [Japanese Journal of Physiology, 50, 257-265, 2000]

Key words: $\quad$ Cardiac energetics, $E_{\max }$, myocardial $\mathrm{O}_{2}$ consumption, pressure-volume area, PVA.

The positive inotropism of caffeine $(0.1-5 \mathrm{mmol} / \mathrm{l})$ has a considerable $\mathrm{O}_{2}$ wasting effect $[1,2]$ and various approaches have elucidated its mechanisms [2-4]. However, this $\mathrm{O}_{2}$ wasting effect remains to be characterized by the $E_{\max }-\mathrm{PVA}-V_{2}$ relation, which at present seems one of the most powerful integrative frameworks of cardiac mechanoenergetics [5, 6]. Here, $E_{\max }$ is the end-systolic maximum pressure-volume ratio (or elastance) and serves as an index of contractility reasonably independent of cardiac loading conditions [5-7]. PVA is the systolic pressure-volume $(P-V)$ area that quantitates the total mechanical energy of ventricular contraction $[5,6,8] . V_{\mathrm{O}_{2}}$ is $\mathrm{O}_{2}$ consumption by ventricular contraction. The $E_{\max }-\mathrm{PVA}-V \mathrm{O}_{2}$ framework is compatible with the Starling law of the heart [9]. In this framework, the $\mathrm{O}_{2}$ cost of $E_{\max }$ serves as a physiologically sound quantitative measure of the $\mathrm{O}_{2}$ demand for unit increment in $E_{\max }[5,10-16]$.

We have already shown that calcium, catecholamines, digitalis, and phosphodiesterase inhibitors (DPI 201-106, OPC-8212, EMD-53998, milrinone, sulmazole, etc.) have comparable $\mathrm{O}_{2}$ cost of $E_{\max }$ in the normal canine heart $[5,10,11,15]$. We have also shown that the $\mathrm{O}_{2}$ cost of $E_{\max }$ increases by $50-100 \%$ of the control in failing hearts produced by myocardial acidosis [12], postischemic and post-acidotic

Received on November 12, 1999; accepted on February 25, 2000

Correspondence should be addressed to: Hiroyuki Suga, Research Institute, National Cardiovascular Center, 5-7-1 Fujishirodai, Suita, Osaka, 565-8565 Japan. Phone: +81-6-6833-5211, Fax: +81-6-6833-1421, E-mail: hsuga@ri.ncvc.go.jp 
stunning [13, 14], and ryanodine treatment [16]. Positive inotropism of cardiac cooling decreased the $\mathrm{O}_{2}$ cost of $E_{\max }$, whereas negative inotropism of cardiac warming increased it at a $Q_{10}$ of 2-3 between 30 $40^{\circ} \mathrm{C}[17,18]$. However, no literature has yet documented a positive inotropism that has an abnormally high $\mathrm{O}_{2}$ cost of $E_{\max }$. We suspected caffeine to be such an agent on the basis of its known pharmacological mechanisms, as listed in the following [2-4, 19-25].

Caffeine has complex pharmacological mechanisms for positive inotropism even after $\beta$-blockade [2-4, 19-25]. It increases cAMP by phosphodiesterase inhibition and augments the phosphorylation of various contractility-related proteins $[2,19,20,25]$. It also increases the open probability of the ryanodine-sensitive calcium $\left(\mathrm{Ca}^{2+}\right)$ release channels in the sarcoplasmic reticulum (SR) [21, 23, 25]. This causes futile $\mathrm{Ca}^{2+}$ cycling analogous to ryanodine treatment at nanomolar concentrations, increasing the $\mathrm{O}_{2}$ cost of $E_{\max }$ [16, 26]. On the other hand, caffeine increases the $\mathrm{Ca}^{2+}$ responsiveness of contractility $[3,4,19,22]$ so that a smaller amount of released $\mathrm{Ca}^{2+}$ achieves a comparable contractility. This compensates for the increased $\mathrm{O}_{2}$ cost of $E_{\max }$ due to the futile $\mathrm{Ca}^{2+}$ cycling. Therefore, the $\mathrm{O}_{2}$ wasting for excitation-contraction (E-C) coupling with caffeine should be determined as the balance of at least these opposing effects. The $\mathrm{O}_{2}$ cost of $E_{\max }$ seems an appropriate measure to evaluate the net of these complex effects. However, the $\mathrm{O}_{2}$ wasting effect of caffeine remains to be elucidated by the $\mathrm{O}_{2}$ cost of $E_{\max }$ in a whole beating heart.

We tested our hypothesis that the $\mathrm{O}_{2}$ cost of $E_{\max }$ could characterize integratively the $\mathrm{O}_{2}$ wasting effect of caffeine despite its complex inotropic mechanisms. We used the left ventricle (LV) of a standard excised, cross-circulated canine heart preparation [10-16]. We found that the $\mathrm{O}_{2}$ cost of $E_{\max }$ was $40 \%$ greater on average for caffeine than for calcium. We were thus able to obtain a quantitative result indicating evidently that caffeine, even at concentrations lower than $1 \mathrm{mmol} / l$, is a mechanoenergetically unique, $\mathrm{O}_{2}$-wasting, positive inotropic agent. This result supported our present hypothesis.

\section{MATERIALS AND METHODS}

$\boldsymbol{E}_{\max }-\mathrm{PVA}-\mathrm{VO}_{\mathbf{2}}$ framework. The $E_{\max }-\mathrm{PVA}-\mathrm{VO}_{2}$ framework enables an integrative assessment at the organ level of myocardial mechanoenergetics in different contractilities (Fig. 1) [5, 6]. $E_{\max }$ represents the recruitability of force-generating crossbridges per unit increase in ventricular volume according to the Starling law $[6,9]$. PVA quantitates the total mechanical
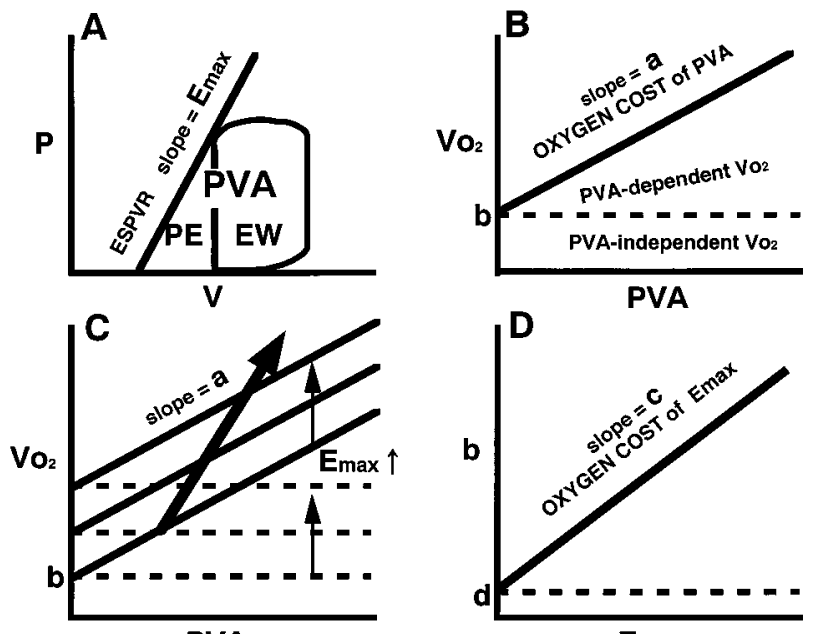

Emax

Fig. 1. $E_{\max }-\mathrm{PVA}-\mathrm{VO}_{2}$ framework of the left ventricle (LV). A: LV pressure-volume $(P-V)$ diagram, explaining the definitions of $E_{\max }$ as an index of ventricular contractility and PVA as a measure of total mechanical energy of contraction. B: $V \mathrm{O}_{2}-\mathrm{PVA}$ relation in a constant $E_{\max }$. $\mathrm{O}_{2}$ cost of PVA (a): slope of the $\mathrm{VO}_{2}-\mathrm{PVA}$ relation. PVA-independent $V \mathrm{O}_{2}(b): V_{2}$ intercept of the $V_{O_{2}}-P V A$ relation. C: $V O_{2}-P V A$ relations with comparable slopes (a) but different $V_{2}$ intercepts $(b)$ at three different $E_{\max }$ levels. The steeper $V_{O_{2}}-\mathrm{PVA}$ relation (heavy arrow) is a composite $\mathrm{VO}_{2}-\mathrm{PVA}$ relation traversing the three standard $V_{O_{2}}-P V A$ relations at different $E_{\max }$ levels. D: PVA-independent $V_{2}(b)-E_{\max }$ relation. $\mathrm{O}_{2}$ cost of $E_{\max }(c)$ : slope of the PVA-independent $V_{2}(b)-E_{\max }$ relation. Basal metabolism $(d)$ : PVA-independent $V_{2}$ intercept. For more details, see text.

energy produced by crossbridge cycling in each ventricular contraction [5]. PVA closely correlates with ventricular $\mathrm{VO}_{2}$ per beat in a steady state (Fig. 1B). The slope $(a)$ of the $V \mathrm{O}_{2}$-PVA relation represents the $\mathrm{O}_{2}$ cost of PVA, and the $\mathrm{OO}_{2}$ intercept $(b)$ represents PVA-independent $\mathrm{VO}_{2}$. The $\mathrm{VO}_{2}$ above basal metabolism is primarily for $\mathrm{Ca}^{2+}$ handling in the E-C coupling [26-30]. The PVA-dependent $V_{2}$ above $b$ seems exclusively related to crossbridge cycling [5].

The $V_{\mathrm{O}_{2}}$-PVA relation usually ascends or descends in parallel with an increase or decrease in $E_{\max }$ with conventional inotropism (Fig. 1C). When $E_{\max }$ increases at a fixed ventricular volume, a $\mathrm{VO}_{2}$-PVA working point ascends along a steeper line traversing the parallel "standard" $\mathrm{VO}_{2}$-PVA lines. The steeper line is called a "composite" $\mathrm{VO}_{2}$-PVA line.

The elevation of the standard $\mathrm{VO}_{2}$-PVA relation closely correlates with $E_{\max }$ (Fig. 1D). The slope (c) of this PVA-independent $V \mathrm{O}_{2}-E_{\max }$ relation represents the $\mathrm{O}_{2}$ cost of $E_{\max }$. Even a single composite $V \mathrm{O}_{2}-\mathrm{PVA}$ line reflects the $\mathrm{O}_{2}$ cost of $E_{\max }$ [14]. This cost quantitates the energy wasting of the E-C coupling $[5,6$, 26-30].

The $\mathrm{O}_{2}$ cost of $E_{\max }$ is comparable among conven- 
tional inotropic agents despite their different pharmacological mechanisms [5, 10, 11, 15]. However, postischemic stunning [14, 31], acidosis [12], postacidotic stunning [13] and ryanodine treatment [16, $26,29]$ increase this cost by $50-100 \%$. Thus, our $E_{\max }-\mathrm{PVA}-V \mathrm{O}_{2}$ framework proved to quantitate the $\mathrm{O}_{2}$ cost of $E_{\max }$ explicitly at the beating whole heart level $[12-14,16]$. For this reason, we used the $E_{\max }-\mathrm{PVA}-$ $V \mathrm{O}_{2}$ framework to characterize the $\mathrm{O}_{2}$ wasting effect of caffeine.

Surgical preparation. We performed experiments on excised cross-circulated canine heart preparations as previously described in detail [5, 10-16]. Briefly, two mongrel dogs $(13-22 \mathrm{~kg})$ were anesthetized with sodium pentobarbital $(30 \mathrm{mg} / \mathrm{kg}$ I.V.) after premedication with ketamine hydrochloride $(7 \mathrm{mg} / \mathrm{kg} \quad$ I.M. $)$. Both dogs were heparinized $(1,000 \mathrm{U} / \mathrm{kg}$ body weight). The heart donor dog $(13.6 \pm 1.3(\mathrm{SD}) \mathrm{kg}$ ) was thoracotomized under artificial ventilation. The left subclavian artery and the right ventricle were cannulated and connected to the bilateral common carotid arteries and external jugular vein, respectively, of the support dog $(17.0 \pm 2.7 \mathrm{~kg})$ with arterial and venous cross-circulation tubing. Both systemic and pulmonary vessels to the heart were ligated. The heart was excised from the chest after starting cross-circulation without interruption of the coronary perfusion.

We opened the left atrium and cut all LV chordae tendineae. A thin rubber balloon with an unstressed volume of $60 \mathrm{ml}$ was fitted into the LV. The balloon was connected to our custom-made volume servo pump (International Servo Data, Tokyo, Japan) and primed with water. A miniature pressure gauge ( $\mathrm{P}-7$, Konigsberg, CA, USA) was placed inside the apical end of the balloon to measure LV pressure.

The cardiac temperature was kept at $35-37^{\circ} \mathrm{C}$ with heaters, and left atrial pacing kept the heart rate constant at $147 \pm 6$ beats $/ \mathrm{min}$. We repeatedly measured coronary arterial $\mathrm{pH}, \mathrm{PO}_{2}$ and $\mathrm{PCO}_{2}$ and corrected them to normal as needed.

$\mathrm{O}_{2}$ consumption. Coronary blood flow was measured with an electromagnetic flowmeter in the coronary venous cross-circulation. Coronary arteriovenous $\mathrm{O}_{2}$ content difference $\left(\mathrm{AVO}_{2} \mathrm{D}\right)$ was measured continuously with our custom-made $\mathrm{O}_{2}$ content difference analyzer (PWA-200S, Shoei-Technica, Chiba, Japan) $[5,10-16] . \mathrm{LV} \mathrm{O}_{2}$ consumption per minute was obtained as the product of the total coronary flow and $\mathrm{AVO}_{2} \mathrm{D}$ and then divided by heart rate to obtain $\mathrm{O}_{2}$ consumption per beat $\left(\mathrm{VO}_{2}\right)$ on an online real-time basis with a computer $[5,10-16]$.

Right ventricular $V_{\mathrm{O}_{2}}$ was minimized by keeping the right ventricle collapsed with coronary venous hydrostatic drainage. The collapsed ventricle had zero PVA and hence no PVA-dependent $V \mathrm{O}_{2}$. LV PVA-independent $\mathrm{VO}_{2}$ was obtained by multiplying the biventricular PVA-independent $V \mathrm{O}_{2}$ with the $\mathrm{LV}$ to total ventricular weight ratio $(0.78 \pm 0.04)$ in each $E_{\max }[6$, 13]. The total ventricular weight was $101.0 \pm 18.0 \mathrm{~g}$, and the LV weight including the interventricular septum was $78.7 \pm 14.3 \mathrm{~g}$.

Contractility index $\left(E_{\max }\right)$. We sampled LV pressure $(P)$ and volume $(V)$ data at 2-ms intervals and processed them with the computer. As shown in Fig. 2, the LV $E_{\max }$ was determined as the end-systolic $P-V$ ratio after subtracting $V_{0}$ (volume at which peak isovolumic $P$ and PVA are zero) from the total volume [8]. We also determined $+\max \mathrm{d} P / \mathrm{d} t$, time to $E_{\max }$, and time to $-\max \mathrm{d} P / \mathrm{d} t$ from the rising phase of $\mathrm{R}$ of the epicardial ECG. The conventional exponential time constant of LVP decay during isovolumic relaxation with an assumption of zero asymptote was also determined.

Pressure-volume area (PVA). We calculated the PVA of each beat from the digitized $P-V$ data on our computer [5, 10-16]. PVA is the area bounded by the systolic $P-V$ segment, end-systolic $P-V$ relation line and end-diastolic $P-V$ relation curves (Figs. 1A and 2). PVA was normalized for $100 \mathrm{~g} \mathrm{LV}$ in $\mathrm{mmHg} \mathrm{ml} \mathrm{beat}{ }^{-1} 100 \mathrm{~g}^{-1}$.

Experimental protocol. We performed the experiments to obtain the $\mathrm{O}_{2}$ cost of both PVA and $E_{\max }$ under caffeine and $\mathrm{Ca}^{2+}$ treatments as follows.

Baseline volume run. First, we performed the volume run to obtain the standard $\mathrm{VO}_{2}$-PVA relation in all eight LVs. Steady-state isovolumic contractions at 6-40 ml were produced in baseline $E_{\max } . V_{2}-\mathrm{PVA}$ data were obtained at several LV volumes.

Control volume run. Next, we gave propranolol at a constant rate of $1-2 \mathrm{mg} / \mathrm{h}$ into the coronary circulation for $\beta$-blockade in all LVs [23]. Steady-state isovolumic contractions were produced again in this controlled $E_{\max }$ run to obtain $V_{\mathrm{O}_{2}}-\mathrm{PVA}$ data at several $\mathrm{LV}$ volumes.

Caffeine and $\mathrm{Ca}^{2+}$ inotropism runs. Then, we performed inotropism runs to compare the effects of caffeine and $\mathrm{Ca}^{2+}$ in all LVs. Here, we fixed LVV at $22.8 \pm 2.5 \mathrm{ml}$. We increased caffeine and $\mathrm{Ca}^{2+}$ infusion rates in steps every $5 \mathrm{~min}$ until $E_{\max }$ nearly doubled. The maximum dose of caffeine was $0.075 \pm 0.016$ $\mathrm{mmol} / \mathrm{min}$, corresponding to a coronary blood concentration of $0.90 \pm 0.45 \mathrm{mmol} / l$ (coronary flow: $110 \pm 42 \mathrm{ml} / \mathrm{min}$ ). The maximum dose of $\mathrm{CaCl}_{2}$ was $0.080 \pm 0.030 \mathrm{mmol} / \mathrm{min}$, corresponding to $1.55 \pm 0.65$ $\mathrm{mmol} / \mathrm{l}$ (coronary flow: $64 \pm 25 \mathrm{ml} / \mathrm{min}$ ). The $\mathrm{Ca}^{2+}$ run 


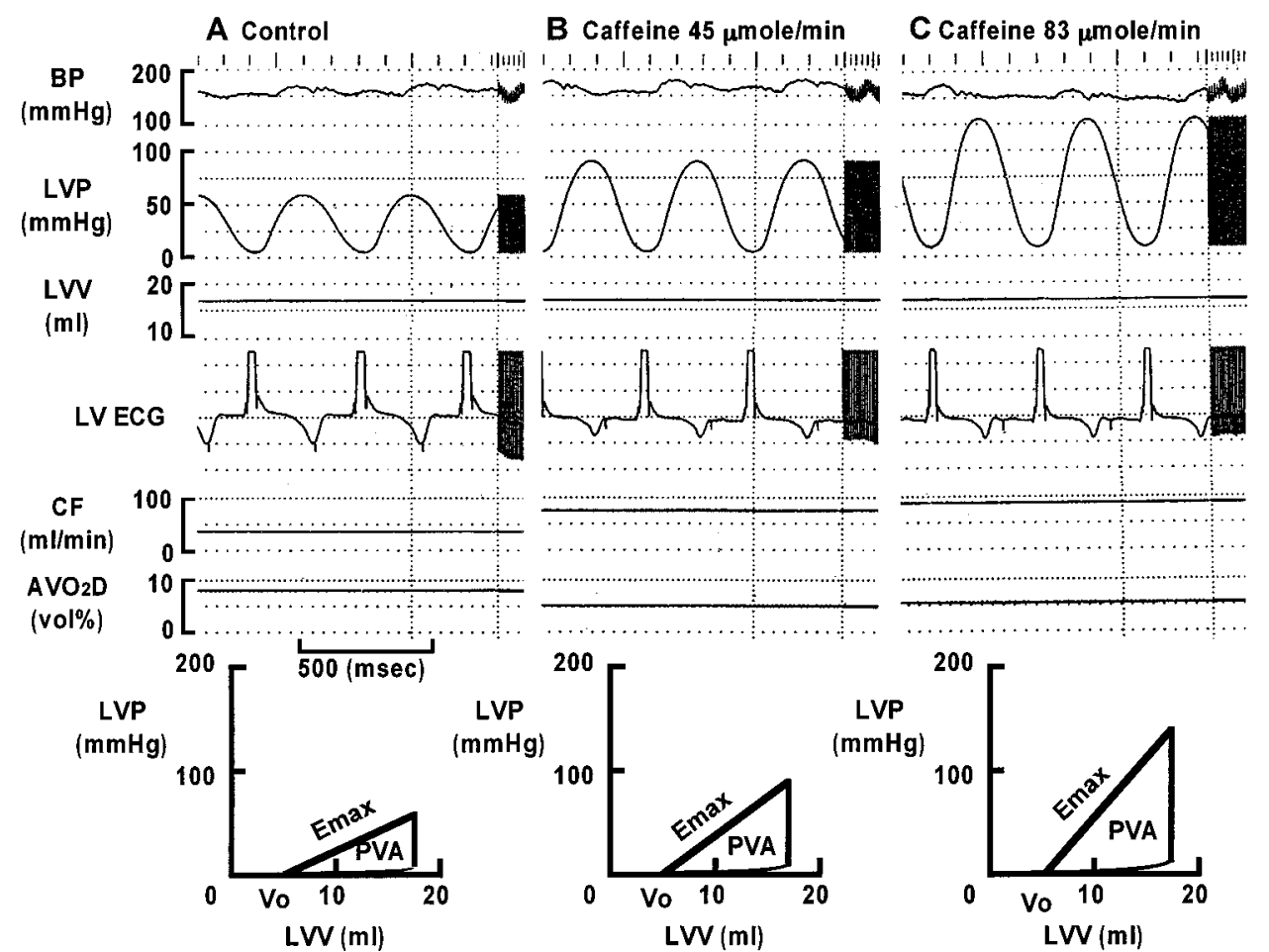

Fig. 2. A representative set of tracings of coronary perfusion blood pressure (BP), isovolumic left ventricular (LV) pressure (LVP), constant LV volume (LVV), LV ECG (saturated QRS waves), coronary blood flow (CF), and coronary arteriovenous $\mathrm{O}_{2}$ content difference $\left(\mathrm{AVO}_{2} \mathrm{D}\right)$. The LVP-LVV diagrams show $E_{\max }$ and PVA. A shows control data. B and C show data under intracoronary caffeine infusion at 0.045 and $0.083 \mathrm{mmol} / \mathrm{min}$, respectively. $V_{0}$ : end-systolic unstressed volume. preceded the caffeine run in five LVs, and vise versa in three LVs.

Inotropism volume runs. We performed caffeine and $\mathrm{Ca}^{2+}$ volume runs at the end of the respective inotropism runs in all LVs. We waited for $15-30 \mathrm{~min}$ until the positive inotropic effects disappeared between the inotropism runs.

$\mathrm{KCl}$ run. Finally, we arrested all hearts at $V_{0}$ to obtain the basal metabolic $\mathrm{VO}_{2}$ by slowly infusing $\mathrm{KCl}$ solution $(0.3 \mathrm{~mol} / \mathrm{l})$ intracoronarily at a rate of $1-2$ $\mathrm{ml} / \mathrm{min}$. This dose corresponded to an estimated intracoronary concentration of $\mathrm{KCl}$ of $10-20 \mathrm{mmol} / \mathrm{l}$.

Data analyses. We analyzed the $E_{\max }-\mathrm{PVA}-\mathrm{VO}_{2}$ data by our routine methodology [5, 10-18]. That which followed is briefly explained here because we explained them elsewhere [5, 10-18].

$\mathrm{O}_{2}$ cost of $\mathrm{PVA}$. We obtained a standard $\mathrm{VO}_{2}-\mathrm{PVA}$ regression line from the $\mathrm{VO}_{2}-\mathrm{PVA}$ data in each volume run by linear regression analysis. Its slope yielded the $\mathrm{O}_{2}$ cost of PVA (a, Fig. 1B) in $\mathrm{ml} \mathrm{O}_{2} \mathrm{mmHg}^{-1} \mathrm{ml}^{-1}$. We obtained a composite $\mathrm{VO}_{2}$-PVA regression line from $\mathrm{VO}_{2}-\mathrm{PVA}$ data in each inotropism run by linear regression analysis.

PVA-independent $\mathrm{VO}_{2}$. We calculated PVA-independent $V \mathrm{O}_{2}$ (intercept $b$ ) of each $V \mathrm{O}_{2}-\mathrm{PVA}$ value during each inotropism run as measured $V_{\mathrm{O}_{2}}$ minus PVAdependent $\mathrm{VO}_{2}$ (a. PVA, Fig. 1B).

$\mathrm{O}_{2}$ cost of $E_{\max }$. We obtained the relation between PVA-independent $V_{\mathrm{O}_{2}}(b)$ and corresponding $E_{\max }$ values at a fixed volume by linear regression analysis of each inotropism run. The slope ( $c$, Fig. 1D) of the regression line yielded the $\mathrm{O}_{2}$ cost of $E_{\max }$ in $\mathrm{ml}$ $\mathrm{O}_{2} \mathrm{ml} \mathrm{mmHg}^{-1}$ beat $^{-1} 100 \mathrm{~g}^{-2}[4,9,11-15]$. Intercept $d$ corresponding to basal metabolism, was $0.012 \pm$ $0.003 \mathrm{ml} \mathrm{O}_{2}$ beat $^{-1} 100 \mathrm{~g}^{-1}$.

Statistics. We compared regression lines in the experimental runs separately for the standard $\mathrm{VO}_{2}-$ $\mathrm{PVA}$, composite $\mathrm{VO}_{2}-\mathrm{PVA}$, and PVA-independent $V \mathrm{O}_{2}-E_{\max }$ relations in each heart by analysis of covariance (ANCOVA). Multiple comparisons of paired values among the runs in all LVs were made by analysis of variance (ANOVA) followed by the least significance difference (LSD) method. $p$ values smaller than 0.05 were considered statistically significant. Data are presented as mean $\pm \mathrm{SD}$.

\section{RESULTS}

Figure 2 shows a representative set of simultaneous tracings of coronary BP (blood perfusion pressure), LVP (pressure), fixed LVV (volume), LV bipolar ECG, $\mathrm{CF}$ (coronary flow) and $\mathrm{AVO}_{2} \mathrm{D}$ during a caffeine inotropism run. We increased the caffeine infusion rate from 0 (A) to $0.045 \mathrm{mmol} / \mathrm{min}$ (B) and maximally $0.083 \mathrm{mmol} / \mathrm{min}$ (C). This corresponded to an intracoronary caffeine concentration of $0.92 \mathrm{mmol} / l$. Caffeine maximally enhanced $E_{\max }$ from 2.4 to 5.5 $\mathrm{mmHg} \mathrm{ml} \mathrm{m}^{-1} 100 \mathrm{~g}$, nearly doubled coronary flow, and considerably decreased $\mathrm{AVO}_{2} \mathrm{D}$. The $\mathrm{Ca}^{2+}$ inotropism run after the caffeine inotropism run increased $E_{\max }$ 
Table 1. Mechanoenergetics compared between caffeine and $\mathrm{Ca}^{2+}$.

\begin{tabular}{|c|c|c|c|c|c|c|}
\hline \multirow{2}{*}{ Inotropism runs } & \multicolumn{3}{|c|}{ Caffeine } & \multicolumn{3}{|c|}{$\mathrm{Ca}^{2+}$} \\
\hline & Pre-caffeine & & Maximum caffeine & Pre-Ca ${ }^{2+}$ & & Maximum $\mathrm{Ca}^{2+}$ \\
\hline $\mathrm{EDV}(\mathrm{ml})$ & $22.8 \pm 2.4$ & & $22.8 \pm 2.4$ & $22.8 \pm 2.4$ & & $22.8 \pm 2.4$ \\
\hline EDP $(m m H g)$ & $4.1 \pm 2.2$ & NS & $4.3 \pm 3.4$ & $4.3 \pm 3.8$ & NS & $3.5 \pm 2.6$ \\
\hline $\mathrm{ESP}(\mathrm{mmHg})$ & $64 \pm 15$ & $<$ & $112 \pm 13$ & $69 \pm 21$ & $<$ & $111 \pm 15$ \\
\hline $\mathrm{CF}(\mathrm{ml} / \mathrm{min})$ & $50 \pm 30$ & $<$ & $110 \pm 41$ & $59 \pm 36$ & NS & $63 \pm 25$ \\
\hline $\mathrm{AVO}_{2} \mathrm{D}(\mathrm{vol} \%)$ & $9.9 \pm 3.8$ & $>$ & $6.0 \pm 2.0$ & $8.2 \pm 2.8$ & $<$ & $9.8 \pm 2.7$ \\
\hline$E_{\max }(\mathrm{mmHg} / \mathrm{ml})$ & $3.2 \pm 0.8$ & $<$ & $5.6 \pm 0.7$ & $3.4 \pm 1.0$ & $<$ & $5.5 \pm 0.6$ \\
\hline PVA (mmHg ml) & $635 \pm 181$ & $<$ & $1,123 \pm 217$ & $682 \pm 239$ & $<$ & $1,150 \pm 240$ \\
\hline $\mathrm{VO}_{2}$ intercept $\left(\mathrm{ml} \mathrm{O}_{2} /\right.$ beat $)$ & $0.0194 \pm 0.0031$ & $<$ & $0.0266 \pm 0.0045$ & $0.0189 \pm 0.0028$ & $<$ & $0.0242 \pm 0.0045$ \\
\hline$T_{\max }(\mathrm{ms})$ & $183+14$ & NS & $185+13$ & $185+11$ & $>$ & $175+10$ \\
\hline$+\max \mathrm{d} P / \mathrm{d} t(\mathrm{mmHg} / \mathrm{s})$ & $694+152$ & $<$ & $1,193+138$ & $738+198$ & $<$ & $1,238+180$ \\
\hline$-\max \mathrm{d} P / \mathrm{d} t(\mathrm{mmHg} / \mathrm{s})$ & $530+142$ & $<$ & $995+100$ & $590+205$ & $<$ & $1,020+158$ \\
\hline Time to $-\max \mathrm{d} P / \mathrm{d} t(\mathrm{~ms})$ & $289+18$ & NS & $286+24$ & $295+23$ & $>$ & $271+18$ \\
\hline$\tau(\mathrm{ms})$ & $51.2+12.1$ & $>$ & $40.1+5.4$ & $47.6+10.1$ & $>$ & $37.7+6.4$ \\
\hline
\end{tabular}

All values are normalized for $100 \mathrm{~g} \mathrm{LV.} \mathrm{EDP,} \mathrm{end-diastolic} \mathrm{pressure} \mathrm{at} \mathrm{the} \mathrm{preset} \mathrm{isovolumic} \mathrm{volume;} \mathrm{ESP,} \mathrm{end-systolic} \mathrm{pres-}$ sure; $\mathrm{CF}$, coronary blood flow; $\mathrm{AVO}_{2} \mathrm{D}$, coronary arteriovenous $\mathrm{O}_{2}$ content difference; $E_{\max }$, end-systolic maximum elastance or pressure/volume ratio; PVA, systolic $P-V$ area as a measure of total mechanical energy of ventricular contraction; $V \mathrm{O}_{2}$ intercept, $\mathrm{VO}_{2}$ (or $y$ )-axis intercept of the $\mathrm{VO}_{2}-\mathrm{PVA}$ regression line; $T_{\max }$, time to $E_{\max }$ from the onset of contraction; $+\mathrm{max} \mathrm{d} P / \mathrm{d} t$, maximum positive value of time derivative of LV pressure; - max $\mathrm{d} P / \mathrm{d} t$, maximum negative value of time derivative of $\mathrm{LV}$ pressure; time to $-\max \mathrm{d} P / \mathrm{d} t$, time to $-\max \mathrm{d} P / \mathrm{d} t$ from the onset of contraction; $\tau$, time constant of isovolumic relaxation pressure segment after $-\max \mathrm{d} P / \mathrm{d} t$; $<$ or $>$, significantly smaller or larger at $p<0.05$ by paired $t$-test; NS, insignificant. Maximum caffeine: $0.075 \pm 0.016 \mathrm{mmol} / \mathrm{min}$. Maximum $\mathrm{Ca}^{2+}: 0.080 \pm 0.030 \mathrm{mmol} / \mathrm{min}$.

from 2.2 to $5.5 \mathrm{mmHg} \mathrm{ml}^{-1} 100 \mathrm{~g}$ in this LV. PVA increased in proportion to $E_{\max }$ as shown by the $P-V$ diagrams.

Table 1 compares cardiac mechanoenergetics before and during the caffeine and $\mathrm{Ca}^{2+}$ inotropism runs at a fixed LV volume in all LVs. The pre-caffeine and pre- $\mathrm{Ca}^{2+}$ control data were obtained after $\beta$-blockade. Both maximum-caffeine and maximum- $\mathrm{Ca}^{2+}$ data were obtained at a maximally enhanced $E_{\max }$. The $E_{\max }$ data evidently indicate comparable positive inotropism by caffeine and $\mathrm{Ca}^{2+}$. However, caffeine inotropism contrasted with $\mathrm{Ca}^{2+}$ inotropism by a nearly doubled coronary flow, a nearly $40 \%$ decreased $\mathrm{AVO}_{2} \mathrm{D}$, and unchanged $T_{\max }$ and time to $-\max \mathrm{d} P / \mathrm{d} t$. Unlike $\mathrm{Ca}^{2+}$, caffeine enhanced lusitropism in terms of $-\max \mathrm{d} P / \mathrm{d} t$ and $\tau$.

Figure 3 shows a representative set of the standard $\mathrm{VO}_{2}$-PVA relations in baseline, control, $\mathrm{Ca}^{2+}$, and caffeine volume runs in an LV. Their slopes were not significantly different from each other (ANCOVA). The relation first descended from baseline to control and then ascended in both caffeine and $\mathrm{Ca}^{2+}$ volume runs. The caffeine and $\mathrm{Ca}^{2+}$ regression lines were significantly higher than the control (ANCOVA). The other $\mathrm{LVs}$ showed similar $\mathrm{VO}_{2}$-PVA relations. The slope of each line yielded the $\mathrm{O}_{2}$ cost of PVA. Its $V_{\mathrm{O}_{2}}$ intercept was the PVA-independent $\mathrm{VO}_{2}$.

Figure 4A shows that the $\mathrm{O}_{2}$ cost of PVA had no

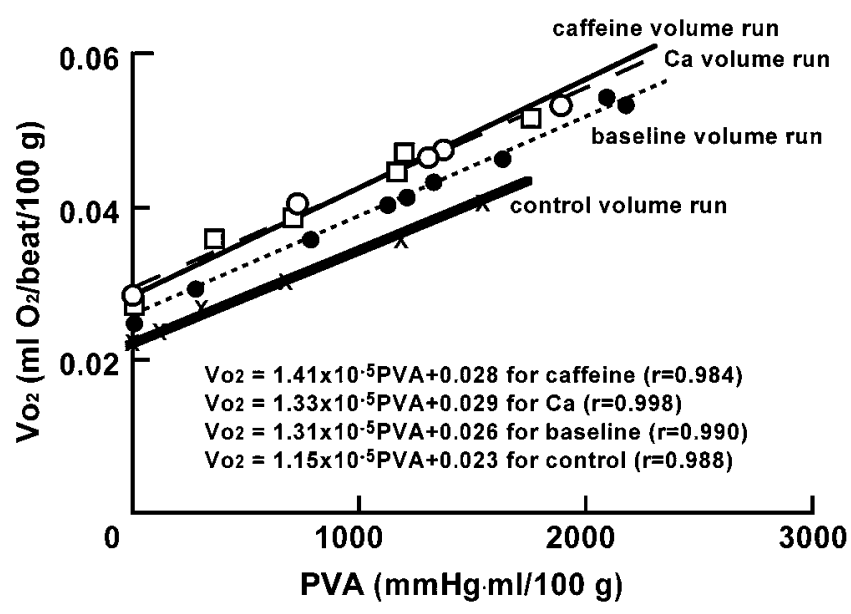

Fig. 3. A representative set of standard $\mathrm{VO}_{2}-\mathrm{PVA}$ regression lines in the baseline volume run (dotted line, solid circles), control (post- $\beta$-blockade) volume run (thick solid line, crosses), caffeine volume run (thin solid line, squares) and $\mathrm{Ca}^{2+}$ volume run (dashed line, open circles) in one LV. Equations indicate linear regression. $r$ : correlation coefficient.

significant difference among the three volume runs in all LVs (ANOVA). Figure 4B shows that $V_{\mathrm{O}_{2}}$ intercept significantly increased from the control in both caffeine and $\mathrm{Ca}^{2+}$ volume runs, but had no significant difference between the caffeine and $\mathrm{Ca}^{2+}$ volume runs in all the LVs (ANOVA).

Figure $5 \mathrm{~A}$ compares the composite $\mathrm{VO}_{2}$-PVA re- 
A

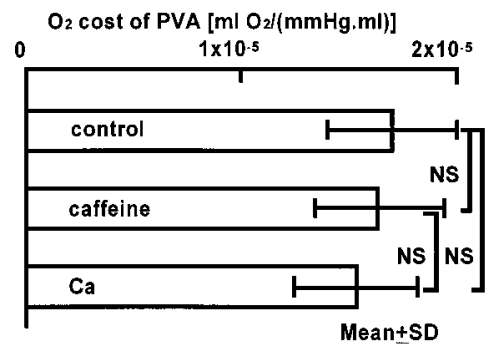

B

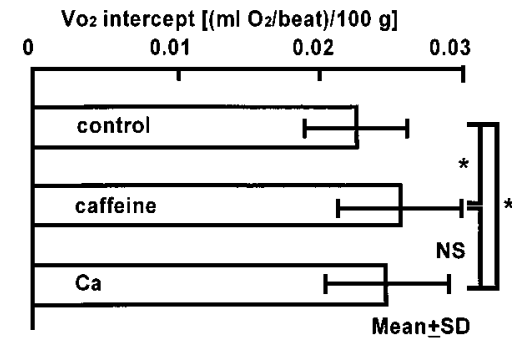

Fig. 4. $\mathrm{O}_{2}$ cost of PVA (A) and $\mathrm{VO}_{2}$ intercept $(B)$ in control (post- $\beta$-blockade), caffeine, and $\mathrm{Ca}^{2+}$ volume runs (from top down) in all eight LVs. NS: insignificant. * $p<$ 0.05 (ANOVA).
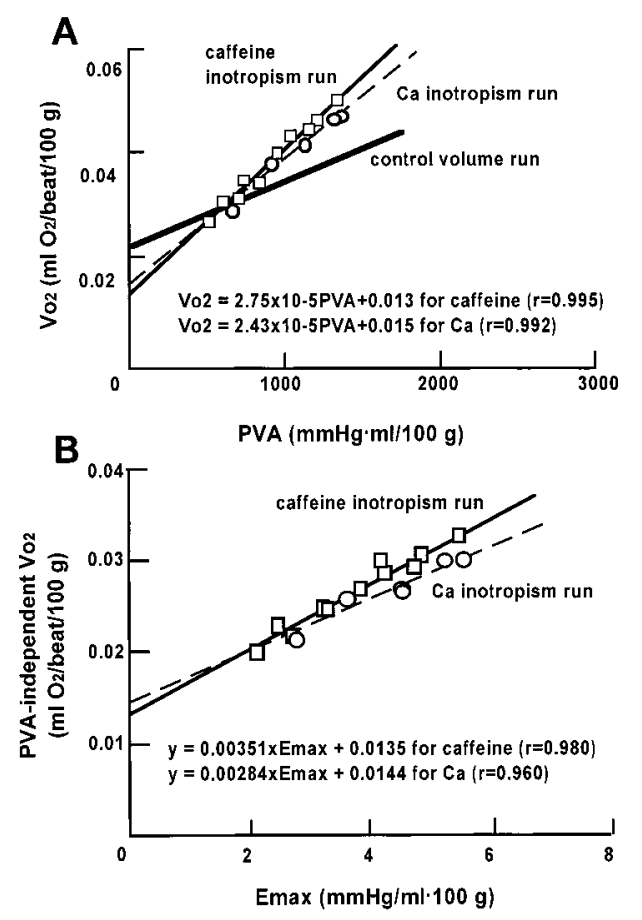

Fig. 5. A: A representative set of the composite $\mathrm{VO}_{2}-$ PVA regression lines in the caffeine (solid line, squares) and $\mathrm{Ca}^{2+}$ (dashed line, circles) inotropism runs in the same LV as in Fig. 3. The standard $\mathrm{VO}_{2}-\mathrm{PVA}$ relation in control volume run (solid line) was transcribed from Fig. 3. Equations indicate linear regression. $r$ : correlation coefficient. B: A representative set of PVA-independent $\mathrm{VO}_{2}-$ $E_{\max }$ regression lines in the caffeine (solid line, squares) and $\mathrm{Ca}^{2+}$ (dashed line, circles) inotropism runs in the same LV shown in A. Equations indicate linear regression. $r$ : correlation coefficient.
A Composite Vo2-PVA slope $\left[\mathrm{ml} \mathrm{O}_{2} /(\mathrm{mmHg} . \mathrm{ml})\right]$

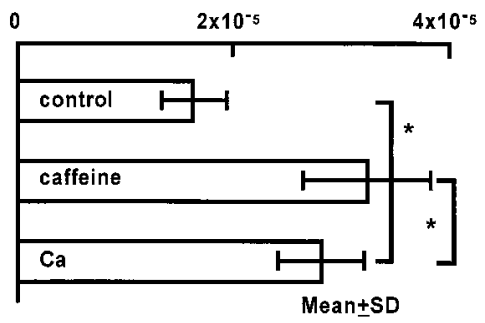

B

$\mathrm{O}_{2}$ cost of Emax

$[(\mathrm{ml} \mathrm{O} /$ beat $\left.) /(\mathrm{mmHg} / \mathrm{ml})) / 100 \mathrm{~g}^{2}\right]$

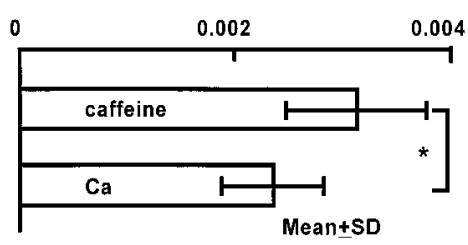

Fig. 6. Composite $\mathrm{VO}_{2}$-PVA slopes (A) in control (post- $\beta$-blockade), caffeine, and $\mathrm{Ca}^{2+}$ volume runs and $\mathrm{O}_{2}$ cost of $E_{\max }(\mathrm{B})$ with caffeine and $\mathrm{Ca}^{2+}$ in all eight LVs. ${ }^{*} p<0.05$ (ANOVA).

gression lines of the caffeine and $\mathrm{Ca}^{2+}$ inotropism runs with the control $V \mathrm{O}_{2}$-PVA regression line in an LV. These composite $\mathrm{VO}_{2}$-PVA regression lines were significantly steeper than the control (ANCOVA). The caffeine inotropism line was significantly steeper than the $\mathrm{Ca}^{2+}$ inotropism line (ANCOVA). Figure 5B compares the slopes of the PVA-independent $\mathrm{VO}_{2}-E_{\max }$ regression lines in the caffeine and $\mathrm{Ca}^{2+}$ inotropism runs (namely the $\mathrm{O}_{2}$ cost of $E_{\max }$ ) in the same LV as in Fig. 5A. This cost was significantly greater with caffeine than with $\mathrm{Ca}^{2+}$ (ANCOVA). The other LVs had similar results.

Figure 6A shows that the caffeine inotropism run had a significantly steeper $(117 \pm 17 \%$ of control, $p<$ $0.05)$ slope of the composite $\mathrm{VO}_{2}-\mathrm{PVA}$ regression line than the $\mathrm{Ca}^{2+}$ inotropism run (ANOVA). These slopes had significantly steeper slopes than the control in all LVs (ANOVA). Figure 6B shows the pooled results that caffeine had a greater $(141 \pm 52 \%$ of control, $p<$ $0.05) \mathrm{O}_{2}$ cost of $E_{\max }$ than $\mathrm{Ca}^{2+}$ in all LVs (ANOVA).

\section{DISCUSSION}

The present results indicate that intracoronary caffeine at concentrations lower than $1 \mathrm{mmol} / l$ always hasan obvious dose-dependent positive inotropism similar to $\mathrm{Ca}^{2+}$ in the canine LV. The $\mathrm{O}_{2}$ cost of mechanical energy (PVA) is comparable between caffeine and $\mathrm{Ca}^{2+}$. However, the $\mathrm{O}_{2}$ cost of $E_{\max }$ as a measure of energy wasting of E-C coupling is significantly ( $40 \%$ on average) greater for caffeine. Therefore, the results sup- 
port our present hypothesis that the $\mathrm{O}_{2}$ cost of $E_{\max }$ integratively characterizes the $\mathrm{O}_{2}$ wasting effect of caffeine despite its complex inotropic mechanisms.

The coexistence of the positive inotropism and the increased $\mathrm{O}_{2}$ cost of $E_{\max }$ in caffeine is unique among the positive inotropic agents we have studied [5, 10-16]. Catecholamines, ouabain, and the phosphodiesterase inhibitors that we had tested have virtually the same $\mathrm{O}_{2}$ cost of $E_{\max }$ as $\mathrm{Ca}^{2+}$ in the normal canine $\operatorname{LV}[5,10,11,15]$. Pathological heart models such as postischemic stunned, acidotic, and post-acidotic stunned LVs as well as ryanodine-treated LV are characterized by a 1.5-2 times increase in $\mathrm{O}_{2}$ cost of $E_{\max }$ [12-14, 16]. However, these failing heart models showed a depressed $E_{\max }$. Therefore, the caffeinetreated LV is the first model characterized by the unique mechanoenergetics consisting of a positive inotropism and its increased $\mathrm{O}_{2}$ cost.

We could speculate about the $\mathrm{Ca}^{2+}$ handling in the caffeine-treated LV, taking advantage of the $E_{\max }$ PVA$\mathrm{OO}_{2}$ framework [5-9, 15]. Either an increased $\mathrm{Ca}^{2+}$ handling, an augmented $\mathrm{Ca}^{2+}$ responsiveness of contractility or both will enhance $E_{\max }$ generally $[5,6$, 26-30]. Either an increased futile $\mathrm{Ca}^{2+}$ cycling, a suppressed $\mathrm{Ca}^{2+}$ responsiveness or both may increase the $\mathrm{O}_{2}$ cost of $E_{\max }$ [26-30]. However, caffeine increases $\mathrm{Ca}^{2+}$ responsiveness [3, 4, 19]. Therefore, the caffeine-induced futile $\mathrm{Ca}^{2+}$ cycling via the SR $[22,23$, $25]$, similar to ryanodine treatment $[16,29]$, could reasonably account for the $\mathrm{O}_{2}$ wasting for contractility. However, caffeine at concentrations lower than 1 $\mathrm{mmol} / l$ enhanced both inotropism $\left(E_{\max }\right)$ and lusitropism $(\tau)$ (Table 1) in the present blood-perfused canine heart, whereas ryanodine, also at nanomolar concentrations, depressed both $E_{\max }$ and $\tau$ in the same type of heart preparation [16]. This difference suggests that $\mathrm{Ca}^{2+}$ responsiveness and cAMP-dependent phosphorylation in addition to futile $\mathrm{Ca}^{2+}$ cycling [3, $4,19,20,24]$, all augmented simultaneously by caffeine at concentrations lower than $1 \mathrm{mmol} / l$, played integratively important roles in the unique mechanoenergetics of caffeine.

Although caffeine increased coronary flow (Table $1)$, the Gregg phenomenon does not accompany the increased $\mathrm{O}_{2}$ cost of $E_{\max }$ [31]. We could not suspect any other cardiodynamic parameters that we studied to be obviously responsible for the increased $\mathrm{O}_{2}$ cost of $E_{\max }$ (Table 1). If caffeine at concentrations lower than $1 \mathrm{mmol} / l$ augments random crossbridge cycling as in the rat myocardium [32], the $\mathrm{O}_{2}$ cost of PVA would increase because random crossbridge cycling consumes more energy without effectively producing PVA. However, we doubt this possibility because the
$\mathrm{O}_{2}$ cost of PVA remained unchanged in the present study (Figs. 3 and 4).

The present results all together seem to suggest the following integratively. The $\mathrm{O}_{2}$ saving effect of caffeine, presumably due to the increased $\mathrm{Ca}^{2+}$ responsiveness with caffeine $[3,4,19,22]$, may be outweighed by the $\mathrm{O}_{2}$ wasting effect of caffeine, presumably due to both futile $\mathrm{Ca}^{2+}$ cycling and augmented cAMP-dependent phosphorylation with caffeine [2, 19-21, 23, 25]. However, the present integrative method has an obvious limitation that these individual pharmacological mechanisms for the $\mathrm{O}_{2}$ saving and wasting effects of caffeine cannot be analyzed reductionistically in the beating whole heart preparation simultaneously. Nevertheless, the present study is worthwhile since conventional reductionistic methods are still unable to elucidate the present integrative results.

Theophylline and sulmazole appear to have the same positive inotropic mechanisms as caffeine, particularly the inhibition of cyclic AMP phosphodiesterase, elevation of cyclic AMP level, and increased myofibrillar $\mathrm{Ca}^{2+}$ sensitivity in canine superfused myocardium preparation [33-36]. Although we have not studied the mechanoenergetics of theophylline, we have found that sulmazole has the same mechanoenergetic effects in the $E_{\max }-\mathrm{PVA}-\mathrm{VO}_{2}$ framework as milrinone, epinephrine, and even ouabain in the canine blood-perfused whole heart preparation [11]. Therefore, caffeine seems to have the oxygen wasting effect that sulmazole does not have in the canine blood-perfused heart. This suggests that the positive inotropic mechanisms of caffeine and sulmazole are not identical, at least in the canine blood-perfused heart preparation we have been using consistently. We would speculate that this difference may be accountable by the futile $\mathrm{Ca}^{2+}$ cycling with caffeine, as discussed above $[21,23,25]$.

The present finding has the following clinical implication. The maximum concentration of caffeine, i.e., 1 $\mathrm{mmol} / l$, used in this study is 10 times greater than the blood concentration, $0.1 \mathrm{mmol} / l$, usually reached in man after drinking a cup of regular coffee containing caffeine of $100 \mathrm{mg} / \mathrm{cup}$ [24, 37]. There are reports that more than 5-10 cups of coffee per day increase the risk of coronary heart disease by $1.4-2.5$ times [38, 39]. If one takes these cups of coffee within a few hours, the blood concentration of caffeine may increase toward $1 \mathrm{mmol} / l$, the maximum concentration of caffeine used in this study. The present study suggests that a greater $\mathrm{O}_{2}$ cost of $E_{\max }$ exists at any increased caffeine concentration up to $1 \mathrm{mmol} / l$, according to the linear composite $\mathrm{VO}_{2}$-PVA and PVA-inde- 
pendent $\mathrm{VO}_{2}-E_{\max }$ relations (Fig. $5 \mathrm{~A}$ and $\mathrm{B}$ ). Therefore, the caffeine-induced positive inotropic effect, accompanied by a significant $\mathrm{O}_{2}$ wasting effect, may partly underlie the dose-dependent increase in the risk of coronary heart diseases.

In conclusion, the $E_{\max }-\mathrm{PVA}-\mathrm{VO}_{2}$ framework has integratively characterized the unique mechanoenergetics of caffeine at intracoronary concentrations lower than $1 \mathrm{mmol} / l$ at the beating whole heart level. Caffeine causes 1.4 times more energy wasting for excitation-contraction coupling than ordinary positive inotropism in the canine heart under $\beta$-blockade.

The first author (T.T.) greatly appreciated the continuous encouragement throughout the period of this study by Prof. Goro Kajiyama of the First Department of Internal Medicine, Hiroshima University School of Medicine, from which T.T. was on leave as a postdoctoral research fellow. This study was partly supported by Grants-in-Aid for Scientific Research (07508003, 08670052, 09307029, 09470009, 09670053, 10044330, 10558136, 10770307, 10877006, 11898028) from the Ministry of Education, Science, Sports and Culture, Research Grants for Cardiovascular Diseases (7C-2, 10C-5, 11C-1, 11C-7) from the Ministry of Health and Welfare, 1997-1998 Frontier Research Grants for Cardiovascular System Dynamics and the 1999 Grant for Cardiovascular Physiome Project from the Science and Technology Agency, and a research grant from Suzuken Memorial Foundation, all of Japan.

\section{REFERENCES}

1. Gibbs CL: Changes in cardiac heat production with agents that alter contractility. Aust J Exp Biol Med Sci 45: 379-92, 1967

2. Hanley PJ, Cooper PJ, and Loiselle DS: Energetic effects of caffeine in face of retarded $\mathrm{Na}^{+} / \mathrm{Ca}^{2+}$ exchange in isolated, arrested guinea pig hearts. Am J Physiol 267: H1663-H1669, 1994

3. Palmer $S$ and Kentish JC: Differential effects of the $\mathrm{Ca}^{2+}$ sensitizers caffeine and CGP 48506 on the relaxation rate of rat skinned cardiac trabeculae. Circ Res 80: 682-687, 1997

4. Powers FM and Solaro RJ: Caffeine alters cardiac myofilament activity and regulation independently of $\mathrm{Ca}^{2+}$ binding to troponin C. Am J Physiol 268: C1348C1353, 1995

5. Suga H: Ventricular energetics. Physiol Rev 70: 247-277, 1990

6. Suga H: Paul Dudley White International Lecture. Cardiac performance as viewed through the pressure-volume window. Jpn Heart J 35: 263-280, 1994

7. Suga $H$, Sagawa K, and Shoukas AA: Load independence of the instantaneous pressure-volume ratio of the canine left ventricle and effects of epinephrine and heart rate on the ratio. Circ Res 32: 314-322, 1973

8. Suga $\mathrm{H}$ : Total mechanical energy of a ventricle model and cardiac oxygen consumption. Am J Physiol 236: H498-H505, 1979

9. Suga H, Goto Y, Futaki S, Kawaguchi O, Yaku H, Hata
$\mathrm{K}$, and Takasago $\mathrm{T}$ : Systolic pressure-volume area (PVA) as the energy of contraction in Starling's law of the heart. Heart Vessels 6: 65-70, 1991

10. Futaki S, Goto $Y$, Ohgoshi $Y$, Yaku H, and Suga $H$ : Similar oxygen cost of myocardial contractility between DPI 201-106 and epinephrine despite different subcellular mechanisms of action in dog hearts. Heart Vessels 7: 8-17, 1992

11. Hata K, Goto Y, Futaki S, Takasago T, Saeki A, Nishioka $\mathrm{T}$, and Suga $\mathrm{H}$ : Effects of milrinone and sulmazole on left ventricular mechanoenergetics in canine hearts. J Card Fail 2: 203-213, 1996

12. Hata K, Goto $Y$, Kawaguchi O, Takasago T, Saeki A, Nishioka T, and Suga H: Hypercapnic acidosis increases oxygen cost of contractility in the dog left ventricle. Am J Physiol 266: H730-H740, 1994

13. Hata K, Takasago T, Saeki A, Nishioka T, and Goto Y: Stunned myocardium after rapid correction of acidosis. Increased oxygen cost of contractility and the role of the $\mathrm{Na}^{+}-\mathrm{H}^{+}$exchange system. Circ Res 74: 795-805, 1994

14. Ohgoshi $Y$, Goto $Y$, Futaki S, Yaku H, Kawaguchi O, and Suga $\mathrm{H}$ : Increased oxygen cost of contractility in stunned myocardium of dog. Circ Res 69: 975-988, 1991

15. Suga $H$, Hisano R, Goto $Y$, Yamada $O$, and Igarashi $Y$ : Effect of positive inotropic agents on the relation between oxygen consumption and systolic pressure volume area in canine left ventricle. Circ Res 53: 306-318, 1983

16. Takasago T, Goto $Y$, Kawaguchi $O$, Hata K, Saeki A, Nishioka $T$, and Suga $H$ : Ryanodine wastes oxygen consumption for $\mathrm{Ca}^{2+}$ handling in the dog heart. A new pathological heart model. J Clin Invest 92: 823-830, 1993

17. Suga H, Goto $Y$, Igarashi $Y$, Yasumura $Y$, Nozawa T, Futaki $S$, and Tanaka N: Cardiac cooling increases $E_{\max }$ without affecting relation between $\mathrm{O}_{2}$ consumption and systolic pressure-volume area in dog left ventricle. Circ Res 63: 61-71, 1988

18. Mikane T, Araki J, Suzuki S, Mizuno J, Shimizu J, Mohri $\mathrm{S}$, Matsubara $\mathrm{H}$, Hirakawa $\mathrm{M}$, Ohe $\mathrm{T}$, and Suga $\mathrm{H}: \mathrm{O}_{2}$ cost of contractility but not of mechanical energy increases with temperature in canine left ventricle. Am J Physiol 277: H65-H73, 1999

19. Blanchard EM, Allen DG, and Alpert NR: The effects of isoproterenol, UDCG115, and caffeine on the heat related to excitation-contraction coupling in heart muscle. Can J Physiol Pharmacol 65: 659-666, 1987

20. Blinks, JR, Olson CB, Jewell BR, and Braveny P: Influence of caffeine and other methylxanthines on mechanical properties of isolated mammalian heart muscle. Evidence for a dual mechanism of action. Circ Res 30: 367-392, 1972

21. Konishi M, Kurihara S, and Sakai T: The effects of caffeine on tension development and intracellular calcium transients in rat ventricular muscle. J Physiol (Lond) 355: 605-618, 1984

22. O'Neill SC, Donoso P, Lamont C, and Eisner DA: The effects of caffeine on cardiac muscle. In: Modulation of Cardiac Calcium Sensitivity. A New Approach to Increasing the Strength of the Heart, ed. Lee JA and Allen DG, Oxford University Press, Oxford, pp 
140-159, 1993

23. O'Neill SC and Eisner DA: A mechanism of the effects of caffeine on calcium release during diastole and systole in isolated rat ventricular myocytes. J Physiol (Lond) 430: 519-536, 1990

24. Robertson D, Frolich JC, Carr RK, Watson JT, Hollifield JW, Shand DG, and Oates JA: Effects of caffeine on plasma renin activity, catecholamines and blood pressure. New Eng J Med 298: 181-186, 1978

25. Rousseau E and Meissner G: Single cardiac sarcoplasmic reticulum $\mathrm{Ca}^{2+}$ release channel: activation by caffeine. Am J Physiol 256: H328-H333, 1989

26. Hata Y, Shimizu J, Hosogi S, Matsubara H, Araki J, Ohe T, Takaki M, Takasago T, Taylor TW, and Suga H: Ryanodine decreases internal $\mathrm{Ca}^{2+}$ recirculation fraction of the canine heart as studied by postextrasystolic transient alternans. Jpn J Physiol 47: 521-530, 1997

27. Hosogi S, Araki J, Syuu Y, Suzuki S, Mohri S, Mikane T, Matsubara $\mathrm{H}$, Ohe T, Hirakawa M, and Suga $\mathrm{H}$ : Calcium equally increases internal calcium recirculation fraction before and after $\beta$-blockade in canine left ventricles. Heart Vessels 12: 280-286, 1997

28. Syuu Y, Araki J, Lee S, Suzuki S, Mizuno J, Mohri S, Mikane T, Shimizu J, Takaki M, and Suga H: Effects of $\mathrm{Ca}^{2+}$ and epinephrine on $\mathrm{Ca}^{2+}$ recirculation fraction and total $\mathrm{Ca}^{2+}$ handling in canine left ventricles. Jpn J Physiol 48: 123-132, 1998

29. Shimizu J, Araki J, Mizuno J, Lee S, Syuu Y, Hosogi S, Mohri S, Mikane T, Takaki M, Taylor TW, and Suga H: A new integrative method to quantify total $\mathrm{Ca}^{2+}$ handling and futile $\mathrm{Ca}^{2+}$ cycling in failing hearts. Am J Physiol 275: H2325-H2333, 1998

30. Lee S, Araki J, Imaoka T, Maesako M, Iribe G, Miyaji K, Mohri S, Shimizu J, Harada M, Ohe T, Hirakawa M, and Suga $\mathrm{H}$ : Energy-wasteful total calcium handling under- lies increased $\mathrm{O}_{2}$ cost of contractility in stunned heart. Am J Physiol (in press)

31. Goto Y, Slinker BK, and LeWinter MM: Effect of coronary hyperemia on $E_{\max }$ and oxygen consumption in blood-perfused rabbit hearts. Energetic consequences of Gregg's phenomenon. Circ Res 68: 482-492, 1991

32. Stern MD, Kort AA, Bhatnagar GM, and Lakatta EG: Scattered-light intensity fluctuations in diastolic rat cardiac muscle caused by spontaneous $\mathrm{Ca}^{++}$-dependent cellular mechanical oscillations. J Gen Physiol 82: 119-153, 1983

33. Fujii W, Takaki M, Yoshida A, Ishidate $H$, Ito $H$, and Suga $\mathrm{H}$ : Effects of intracoronary caffeine on left ventricular mechanoenergetics in $\mathrm{Ca}^{2+}$ overload failing rat hearts. Jpn J Physiol 48: 373-381, 1998

34. Kawachi I, Colditz GA, and Stone CB: Does coffee drinking increase the risk of coronary heart disease? Results from a meta-analysis. Br Heart J 72: 269-275, 1994

35. Palmer JR, Rosenberg L, Rao RS, and Shapiro S: Coffee consumption and myocardial infarction in women. Am J Epidemiol 141: 724-731, 1995

36. Endoh M, lijima T, and Motomura S: Inhibition by theophylline of the early component of canine ventricular contraction. Am J Physiol 242: H349-H358, 1982

37. Endoh M: The effects of theophylline on aequorin light transients and force in the isolated dog right ventricular myocardium. J Mol Cell Cardiol 26: 87-98,1994

38. Endoh M, Yanagisawa T, Taira N, and Blinks JR: Effects of new inotropic agents on cyclic nucleotide metabolism and calcium transients in canine ventricular muscle. Circulation 73 (Suppl III): III-117-III-133, 1986

39. Blinks JR and Endoh M: Modification of myofibrillar responsiveness to $\mathrm{Ca}^{++}$as an inotropic mechanism. Circulation 73 (Suppl III): III-85-III-98, 1986 